\title{
P136: Multiple strategic approaches to enhance and sustain the hand hygiene compliance
}

\author{
TK Leung \\ From 2nd International Conference on Prevention and Infection Control (ICPIC 2013) \\ Geneva, Switzerland. 25-28 June 2013
}

\section{Introduction}

Hand hygiene $(\mathrm{HH})$ is the single most important practice to prevent hospital acquired infections. Indeed, $\mathrm{HH}$ promotion is one of the important tasks for infection control team (ICT). However there is no single mean to enhance and sustain the $\mathrm{HH}$ compliance for the staff.

\section{Objectives}

To share and prove multiple strategic approaches can enhance and sustain hand hygiene compliance.

\section{Results}

Prince of Wales Hospital (a teaching hospital of the Chinese University of Hong Kong) has adopted WHO HH audit protocol since 2007. Initially the $\mathrm{HH}$ compliance rate was $37 \%$. In the past few years, $\mathrm{HH}$ promotion relied mainly on poster and through the reminder in different hospital meeting.

Since 2011, ICT launched a series of promotion program with more structural and strategic approaches. Apart from posters, banners, foam board stands and screen savers in clinical computer; ICT increased the frequency of $\mathrm{HH}$ audit from yearly to monthly. The reports were sent to each departments with breakdown of compliance rate by ward. To address the problem of poor compliance of doctor, name based audit with monthly feedback to their department heads. This name based audit also applied to staff group with low compliance rate in specific departments until their compliance rate improved.

In addition, ICT provide positive reinforcement; badges or small gifts were given to staff who performs well in hand hygiene compliance. The overall $\mathrm{HH}$ compliance was $86 \%$ in 2012.

Infection Control, Prince of Wales Hospital, Hong Kong, China

\section{Conclusion}

In order to enhance staff's awareness and change of their behavior in $\mathrm{HH}$ practice, multiple strategic approaches were necessary and proved to success.

\section{Disclosure of interest}

None declared.

Published: 20 June 2013

doi:10.1186/2047-2994-2-S1-P136

Cite this article as: Leung: P136: Multiple strategic approaches to enhance and sustain the hand hygiene compliance. Antimicrobial Resistance and Infection Control 2013 2(Suppl 1):P136.

Submit your next manuscript to BioMed Central and take full advantage of:

- Convenient online submission

- Thorough peer review

- No space constraints or color figure charges

- Immediate publication on acceptance

- Inclusion in PubMed, CAS, Scopus and Google Scholar

- Research which is freely available for redistribution

\section{() Biomed Central}

